\title{
Social Science Contributions to BU Focused Health Service Research in West-Africa
}

\author{
Mark Nichter
}

\section{Introduction}

Health social science (HSS) research has contributed in significant ways to our understanding of how rural communities in West Africa perceive and respond to Buruli ulcer (BU), and the challenges facing those involved with BU health service delivery. These challenges range from the need to mount more effective community outreach education programs leading to earlier BU detection to the need to identify and then address predisposing, enabling, and service delivery related factors [1] that result in treatment delay, drop out, and non-adherence. In this chapter, we briefly highlight HSS research that has broadened our knowledge of community response to BU and then consider HSS-inspired BU interventions. Most of the sources we draw upon involve research carried out in Benin, Cameroon, and Ghana. To date, few HSS studies have been conducted in other endemic countries such as Cote d'Ivoire, The Democratic Republic of the Congo, Nigeria and Uganda. ${ }^{1}$ We include in our overview a selection of studies conducted by both social scientists and medical researchers investigating social and cultural factors that influence health care decision-making.

Two things are important to bear in mind at the onset of this review. First, there is considerable cultural variability both within and between countries. It is therefore best not to overgeneralize the findings of one study to an entire country. While we do identify general patterns that emerge in the literature related to overarching themes, these patterns do not necessarily apply to all groups. Second, different studies have employed different research methodologies. These range from in-depth ethnographic research employing participant observation and detailed case studies

\footnotetext{
${ }^{1}$ Two recent studies conducted in Cote' D'ivoire by Konan et al. [2] and Uganda by Pearson [3] are worthy of mention.

M. Nichter $(\square)$

School of Anthropology, University of Arizona, Tucson, AZ, USA
} 
to structured and semi-structured interviews, surveys, and focus groups. The findings of one type of study may differ significantly from another study using different methods even when conducted in the same region. Each method has its own unique contribution. This is one reason social scientists often employ multiple methods and triangulate data to get at different aspects of any social phenomenon. The importance of doing so is demonstrated in a study of BU conducted by Grietens et al. [4], who speak to the value of establishing trust with research participants as a means of getting at sensitive issues related to health care seeking before attempting to conduct a survey.

\section{$2 \quad$ Part One}

We begin with research on factors that influence health care seeking beginning with predisposing factors. More attention is given to this topic than enabling and service related factors because they provide the most insight into how BU is perceived and experienced culturally.

\subsection{Predisposing Factors: Cultural Perceptions of BU Causality, Social Stigma, and Preference for Traditional Healing}

\subsubsection{Cultural Perceptions of BU Causality}

Cultural perceptions of illness causality are best assessed in terms of multiple levels of causality that encompass predisposing, efficient, instrumental, and ultimate causes of illness [5, 6]. Predisposing factors range from social transgressions to vulnerable traits and states. Efficient causes of illness involve agents whose actions reflect intention such as spirits or witchcraft. Instrumental causes of illness, such as insects, worms, or germs, have no intention. Ultimate causes of illness are associated with such things as God's judgement or some notion of fate. Multiple ideas about the cause of an illness often coexist and it is common for efficient causes (agents) held responsible for causing serious or unusual illnesses to be viewed as working through or in concert with instrumental causes. This is particularly the case when the characteristics of an illness associate it with malevolent intent. In the case of BU, the unusual physical characteristics of BU-ulceration, long term suffering without death, and the negative social and economic hardship associated with the disease-lead many to consider it unnatural even when biomedical treatment is accepted.

Community members often maintain "what if" subjunctive reasoning $[7,8]$ when considering possible causes of an illness and may draw attention to one type or level of causality at a particular time for any of a variety of reasons. For example, drawing attention to mystical causes of a case of BU may entail rationalization for a course of action or involve the moral identity of the afflicted, a decision maker, the household, or even an entire community when illness etiology indexes cultural affiliation or 
difference. Disease attribution may also be a means of "othering" a population. For example in Cote d'Ivoire, a country in which both physical and mystical causes of BU are thought to exist, a perceived rise in the number of BU cases has been attributed to an influx of migrant workers from other West African countries. These populations are thought to somehow harbor the causative agent of the disease. Notably, the importance of identifying an efficient cause of a "sent" illness (like witchcraft or sorcery) is generally not to seek retribution from a specific person or group. It is rather to give an unusual event some sense of coherence. What follows is a brief overview of how BU is perceived by members of the three index countries along with observations on the extent to which illness perceptions influence health care seeking behavior.

\section{Benin}

Mulder et al. [9] interviewed 153 former/active BU patients (107 treated at hospital, 46 by healers) in Southern Benin about their perceptions of BU causality using a semi structured questionnaire. Fifty-eight percent of former patients reported attributing their illness to witchcraft, often for reasons associated with jealousy. However, only $13 \%$ reported that their perception of causality was an important factor in health care decision making when directly asked if such was the case.

Aujoulat et al. [10] carried out a more in-depth community based study of BU causality in the same region. Community members exposed to BU education as well as several health workers maintained the perception that BU-like symptoms could either be signs of a natural disease or an induced disease (sasa) caused by sorcery, witchcraft, or a curse only treatable by healers. Community members generally relied on diagnosis by treatment. The underlying cause of one's illness was thought to become apparent based on the aliment's response to different types of treatment and the trajectory of the illness over time. Notably, in this study, women were far more likely to ascribe BU-like symptoms to natural causes in part because children are often affected. Children are not seen as embroiled in problematic social relations associated with jealousy or any social infraction that might lead to witchcraft or sorcery.

One of the most common natural causes of BU recognized by women was worms. Informants described worms as a possible instrumental cause of BU linked to predisposing factors such as body weakness, fatigue, or environmental factors. However, they did not discount the idea that worm activity might be related to an efficient cause interfering with wound healing. The researchers also explored perceptions of contagion. They found that contagion was commonly related to the foul smell of a necrotizing BU-related wound. Notably, while some community members and health workers feared that BU might be contagious, most women who cared for a child with BU did not believe this to be the case because they had been in close proximity to an afflicted child and not gotten sick. Healers contributed to the perception that BU was contagious by insisting that a patient should remain in isolation during treatment. Notably, a major factor underlying why children having BU were kept out of school by some parents was fear others might consider the child contagious. 
A third study by Kpadonou et al. [11] further documented differences of opinion about causality among a sample of 244 former BU patients treated at Allada Hospital and residing within a $100 \mathrm{~km}$ radius of the hospital. This study found that while a majority of adults and teens attributed BU to witchcraft, a majority of children perceived BU to have natural causes. The authors attributed this difference to children's exposure to health education messages while being treated in hospital. Among teens and elders exposed to the same messages, cultural beliefs about efficient causes of disease remained salient. Regardless of what cause BU was attributed to, $90 \%$ of all informants stated they did not feel guilt associated with having the disease.

A fourth study by Boyer [12] carried out in Benin's Ouémé River region investigated stories and rumors circulating about BU and its treatment at a local Catholic mission hospital renown for BU lesion excision, and the social relations of BU causal attribution in the context of health care seeking. Boyer's in-depth ethnography of BU included case studies of household decision making related to BU treatment. $\mathrm{He}$ found that in some instances mystical attribution of BU was employed by a male decision maker to justify treatment of a family member by traditional healers instead of treatment at a hospital for pragmatic reasons. In this region of Benin, decentralized care did not exist while Boyer was conducting his research, and going to a hospital resulted in a significant loss of revenue and/or labor on the part of the afflicted and/or a patient caretaker required by the hospital. Focusing on mystical causes of the illness and the need for traditional treatment upheld the moral identity of some decision makers opting for traditional treatment. Notably, Boyer documented cases where there was ambivalence about this decision on the part of other family members. Boyer draws attention to the fact that explanatory models of BU involving mystical causes can sometimes serve as post hoc rationalizations of action or inaction as well as being determinants of health care seeking. He further points to the folly of describing "beliefs" about BU as durable unquestioned ideas fixed in the mind of the afflicted instead of seeing them as ad hoc explanatory models subject to revision given the rich semantic illness network [13] of the Beninese. Ideas about BU, he argues, are hardly fixed and subject to the circulation of stories and rumors about the ailment and its treatment. All of this leads Boyer to caution against simplistically blaming "beliefs" for BU treatment delay and assuming that once beliefs (read superstitions) are addressed through education a preference for hospital care will follow.

A fifth study by Kennell $[14,15]$ conducted among the Aja ethnic group draws attention to why some ethnic groups wait before treating an ulcer to determine its cause and decide on a course of action, a process the Aja refer to as zohwizi. Among the Aja, there is a belief that skin eruptions/wounds may be a sign of Sakpata, the vodun deity of the earth long associated with small pox and measles. If deemed a sign of the spirit's presence, it is believed the wound should not be treated by hospital medicine for fear that the spirit might be angered and the patient face dire consequences. A watch and wait policy is deemed prudent to see if the wound erupts as a common abscess or is seen as unusual. If seen as a sign of Sakpata, the afflicted becomes an initiate in a spirit cult. Notably, while hospital medicines may not be used during the zohwizi process, herbal medicines may be applied to hasten the eruption process. 


\section{Cameroon}

Several ethnographic studies have looked at perceptions of BU causality in Cameroon. A detailed study of BU by Grietens et al. [4] in Cameroon highlights the importance of perceptions of multiple or "double causality." This study found that in Southern Cameroon BU (referred to as atom) is commonly attributed to mystical causes associated with either some type of social infraction or witchcraft. Social infractions include such things as theft or trespassing (knowingly or unknowingly) on someone else's agricultural plot protected by a powerful fetish. Guard fetishes are thought to have the power to inflict particular kinds of illnesses, including atom. Sorcery may also cause atom. Sorcery operates through antisocial malignant forces present in an invisible world $(e v u)$. These forces may be controlled and used by either a sorcerer or a healer. They may also be unconsciously present within some people and only become active at night when they are asleep. The characteristics of BU (a wound that does not heal, becomes more severe, and inflicts immense suffering) match the imagery of how people think sorcery operates. A common perception is that in order for a sorcerer to gain power to inflict suffering and in order for a healer to gain power to engage in "night battles" with malevolent forces, sacrifices must be made to strengthen the $e v u$ under their control. One way to do so is through the mystical eating of flesh, even the flesh of family members. Slow progressing BU wounds appearing on the limbs of children as well as adults are thought to be evidence of such flesh eating.

Atom is also thought to have a natural origin related to insect bites, especially the bites of horseflies that fester and become more severe. Some community members exposed to outreach education programs have come to think of these wounds as being infected with microbes. Others perceive these insects to be sent by sorcerers to inflict harm and negatively influence disease progression. The possibility of "double causality" is shared by health staff who maintain an open mind when patients express a desire to seek the assistance of traditional healers while being treated at hospital. This is especially the case when the healing process is not going well. A point emphasized by Grietens et al. is that although perceptions of "double causality" are strong in the region, they are not necessarily the major reason for treatment delay at hospitals and health posts.

A study conducted by Awah et al. [16] in the Bankim region of Cameroon found perceptions of BU causality that are similar, yet distinct from those described in the Southern region of the country. BU like symptoms are seen as possibly having a natural cause, being the sign of a powerful spirit (mbouati), or being caused by witchcraft. Natural causes of the disease are associated with changes in ecology resulting from the building of a large dam in the region, and the introduction of rice cultivation. While residents recognize that the illness has become more common following these events, the instrumental cause of the disease is not understood. Mbouati is a spirit affliction that gives special powers to the afflicted, powers that some of the afflicted may not want to relinquish. Informants across several ethnic groups inhabiting the area voiced the opinion that both mbouati and BU co-existed, and that only traditional healers could determine the difference between the two as well as afflictions caused by witchcraft. Only the most powerful of healers, it is 
thought, can transform a mystical ailment into a chronic physical ulcer (nbong) amenable to successful treatment by herbs or hospital medications. Furthermore, when a wound does not heal when treated it is conjectured that mbouati may be toying with healers or health staff and leading them to believe their treatment is successful in early stages only to undermine their efforts latter.

Local observation that BU-related diseases have increased as a result of ecological and social change is a subject investigated by Giles-Vernick et al. [17] in the central region of Cameroon. Adopting an ethno historical perspective and the use of multiple methodologies ranging from in-depth interviews to group discussions, these researchers investigated the circumstances that have led to a widely held perception that the number of cases of atom have steadily increased during the last two to four decades. An increase in the number of atom cases is associated with ruptured social relations that took place at a time of heightened environmental degradation and ecological decline as well as rising economic hardship, competition, and jealousy. Atom is seen as a sign and symptom of diminished eding, a term that indexes both love and social cohesion leading to fruitful and productive ecological extraction by community members. The researchers note that social, environmental, and ecological disruption are perceived to have provoked and expanded the prevalence of atom through both natural and mystical causes. This study calls our attention to the necessity of studying NTDs in a broader "One world one health" context [18] attentive to both political ecology and those factors leading to structural vulnerability. In the case of BU, this entails the need to document how changes in the environment and shifts in social relations associated with such factors as structural adjustment policies and changing cropping patterns, contribute to disease susceptibility and increased exposure to the pathogen responsible for BU.

\section{Ghana}

The greatest number of social science studies of BU have been carried out in Ghana. A few studies of causality may be highlighted to illustrate the range of observations documented. A large community-based study of local perceptions of BU was carried out by Renzaho et al. [19] in Ga district. Ten percent of the district was surveyed and seven focus groups conducted. The survey found that $53 \%$ of informants had no idea of the cause of BU, $16 \%$ thought it might be caused by drinking nonpotable water, $8 \%$ by poor hygiene and unclean surroundings, and $6 \%$ by swimming or wading in ponds. Only $5 \%$ of participants reported that BU might be caused by witchcraft. During focus groups, however, witchcraft surfaced as a common possible cause of BU and a major source of concern. The survey also suggested that children were far more likely to think BU was contagious than adults.

Ackumey et al. [20, 21] investigated perceptions of BU among those afflicted with BU in both the pre-ulcer and ulcer state in West and South Ga municipalities near Accra. They employed an explanatory model interview guide adapted for BU research. The patient-based data generated in this study was quite different from the community-based survey data generated by the aforementioned study. In the preulcer state, respondents commonly reported behavior-based BU causality, especially swimming in ponds and rivers. However, informants who did not engage in 
such behaviors questioned how this could be the cause of the illness. Still others questioned how this could be the major cause of BU when so many people who had contact with the same water sources did not become ill. Half of all informants believed their condition might be related to drinking unclean water, a general (not BU-specific) health message repeatedly heard from health workers. Many other informants attributed their ulcers to small wounds and insect bites that became aggravated as a result of their scratching them. About a third of all informants stated they had no idea of the cause of their condition. For those with large ulcers, witchcraft was the most common cause reported followed by swimming in rivers, weakness of blood, and drinking unclean water. Weak blood was reported to be a common cause of BU among children.

Notably, the authors found that $40 \%$ of informants with pre-ulcers and $50 \%$ of those with ulcers said their condition could not have been prevented because witchcraft cannot be stopped. Nevertheless, approximately half of all informants stated that avoiding bathing in rivers or ponds prevented the disease. Many noted, however, that this was hardly feasible. The researchers concluded on the basis of their interviews that regardless of perception of causality, those afflicted with BU were willing to seek medical care if it was accessible. The afflicted maintained a pragmatic attitude and were open to trying any treatment that might help them recover from their condition.

Another study of $86 \mathrm{BU}$ patients in Ga district by Owusu and Adamba [22] reported data similar to Ackumey with a few notable differences. In this study, only $15 \%$ of informants attributed the cause of their disease to "enemies"(witchcraft), while 19\% associated the disease with water use, walking through swampy areas while working in the fields (because BU commonly affects the lower limbs), and children swimming in the river. Thirteen percent thought the disease might come from insect bites, but informants could not specify which insect might be causing the disease. Of those who reported insect bite as a possible cause, many maintained dual casualty. They found it hard to believe that an insect bite could lead to such a serious illness unless witchcraft was involved. Of those who imagined dual diagnosis, it was deemed prudent to use herbal medicine before hospital medicine to deal with witches first.

A more recent study by Koka [23] in Ga district found that while 78\% of informants $(N=300)$ thought BU had natural causes, $61 \%$ thought BU could be caused by supernatural agents as well. Notably, there was a statistically significant gender difference in perceptions of causality. Sixty nine percent of women reported natural causes of the disease while only $36 \%$ of men did so $(p=0.006)$. Education also proved to be a factor influencing perceptions of causality. Far more respondents with at least primary education (46\%) were likely to report that Buruli ulcer can be caused by both natural and supernatural causes when compared to those with no education $(29 \%)(p<0.001)$. Moreover, those with at least primary education were far more likely to report only natural causes than those with no education.

Stienstra et al. [24] conducted a study of BU in three regions of Ghana (Agogo, Denkyira, and Amansie districts) and interviewed BU patients at hospitals as well as community members. More than half of all respondents associated poor personal hygiene with the disease, but many others thought this was not possible. They 
observed that people with good hygiene suffered from the disease and that others with very poor hygiene living in the same village did not experience the disease. Nearly half of all respondents also identified the environment as a possible risk factor for BU, especially walking through swampy areas and being bitten by insects that lead one to scratch and open the skin to diseases. Only a few people mentioned drinking water or eating contaminated food as possible causes of BU. Twenty-three percent of all respondents feared BU might be contagious in some way (touch, clothing, flies, feeding, etc.) and a few thought the disease might be sexually transmitted. Fifty-nine percent of respondents thought the disease might be caused by witchcraft, $47 \%$ by a curse, and a few mentioned God's will as an ultimate cause. In the latter case, it was thought that God removed his protection against diseases because of some sin that one had committed. Notably, even though ancestors play an important role in Ghanaian life, they were not mentioned as a cause of BU.

Shifts in environmental landscapes have also been connected to a rise in BU cases in Ghana. Tschakert et al. [25] found that community members in an area of Ghana exposed to artisanal gold mining and illegal logging connected a rise in BU cases to ecological destruction, flooding, and increased bodies of stagnant and/or contaminated water. How these conditions led to increases in the disease was open to considerable conjecture. Notably, community members identified having to cross disturbed spaces to engage in daily activities with increased risk of experiencing BU.

\subsubsection{Stigma and Social Risk}

It has been widely reported in all three index countries that BU is stigmatized. Stigma is a concept that covers a broad range of social responses to a condition or group that is negatively valued. Applied to an illness like BU, it encompasses both felt stigma and enacted stigma. Felt stigma entails a sense of shame, embarrassment, inferiority, and fear of enacted stigma. Enacted stigma entails social exclusion, discrimination, and isolation. Stienstra et al. [24] conducted what has become a landmark study of stigma related to BU attentive to both types of stigma. These researchers employed an eleven-question, pretested instrument to explore social exclusion in various areas of everyday life when one suffered from BU. They administered the instrument to subsamples of both infected and non-infected community members. From their study of three regions of Ghana, they concluded that stigma for BU was pervasive. Half of all afflicted and non-afflicted informants, regardless of educational background, reported that those afflicted with BU were avoided by others, avoidance being slightly higher for men than women. Social avoidance was primarily reported for non-relatives and was particularly high in endemic areas.

Many of the afflicted reported feeling ashamed and stated that they tried to hide their wounds from others. Others, however, were concerned that their illness might be contagious. They displayed their wounds to let others know not to come near. Fear of transmitting BU was related to both natural causes and witchcraft. However, when witchcraft was associated with BU, stigma scores rose appreciably. The study found that not only was BU feared as contagious, but it was also thought to lead to infertility because the disease was perceived to render the blood of the afflicted 
dirty. Having the disease made it more difficult for both the afflicted and family members to marry.

Notably, the study did not find that stigma scores correlated with any pattern of health-care seeking or treatment delay. However, it did find that stigma affected school attendance. Other studies in Ghana have likewise reported that stigma and fear of contamination is particularly strong among school children, leading the afflicted to drop out of school. Koka [23] found that in West Ga district it was not just students who feared that BU might be contagious, but also teachers. As a result, teachers did not intervene when students shunned those having the symptoms of BU.

In Benin, Mulder et al. [9] employed the stigma questionnaire developed by Stienstra et al. and found that about half of all current BU patients interviewed experienced some degree of stigma. Patients treated at health posts and by traditional healers did not report statistically significant differences in levels of stigma. Stigma appeared to decrease post treatment with less than a third of former patients reporting stigma. ${ }^{2}$ Stigma was largely associated with the smell emanating from the wound. Patients often engaged in self-stigmatization, isolating themselves from others out of embarrassment. The actions of traditional healers also reinforced stigma. Many traditional healers demanded isolation while treating BU patients for months and in some cases years. Anthropologists working on a Stop Buruli research project in Benin documented another factor leading to self-isolation: a perception of vulnerability. They found that some patients with open wounds felt vulnerable to witchcraft and other malevolent forces. For this reason, they hid their wounds and when compelled to move through public spaces, would not display bandages.

Some social scientists have cautioned against overemphasizing the role of stigma as a factor causing BU treatment delay. Ribera et al. [27] found that social isolation was common among BU patients in Cameroon, but not a primary factor influencing health care seeking. Paying too much attention to stigma, they argue, deflects attention away from enabling and health service related factors causing delay. They also argue that while BU is commonly associated with social transgressions and witchcraft in central Cameroon, stigma is not the main cause for patients abandoned at the hospitals. Their findings suggest that social isolation and abandonment are often part of a household coping strategy, an attempt to avoid plunging the household into a spiral of impoverishment.

Social risk has been identified as a factor influencing health seeking behavior for BU. Social risk refers to risk to one's reputation that negatively affects present or future social relationships. When a woman is compelled to travel to a clinic for decentralized care or to remain in a hospital for long term BU care she may become the subject of rumors suggesting she is engaging in illicit sexual relations when travelling outside her community. Social risk associated with seeking health care was identified in each of the three index countries, but poorly documented in all but

\footnotetext{
${ }^{2}$ Some studies suggested some types of ongoing social exclusion. A study by de Zeeuw et al. [21] carried out in Benin and Ghana documented persisting social and work participation restrictions among former patients with BU. These restrictions remained long after treatment was completed and wounds had healed.
} 
Benin $[28,29]$. Concern about social risk is one reason women travel to health posts with children or a chaperon, and that children serve as patient care takers at hospitals. Notably, Amoussouhoui et al. [30] found that when outreach education about treatment and decentralized care was made available near one's village in Benin, fear of social risk was reduced.

\subsubsection{Traditional Healers}

It has been widely reported that traditional healers are often a first resort for wound care in all three index countries [10, 16, 24, 31, 32], and that healers often treat BU related wounds for extended periods of time. It is beyond the scope of this chapter to provide a detailed account of the practices of traditional healers. These practices range from exorcism, the placating of spirits, and prayer to herbal treatment, and in many cases provision of both mystical and physical treatment. Researchers like Grietens et al. [4] and Johnson et al. [33] have aptly described some of the more common types of therapy offered by various kinds of healers in all three countries. ${ }^{3}$ Traditional healers often engage in some form of divination to determine the etiology of a wound and then decide whether they should treat the wound or refer the afflicted to another healer who specializes in another type of treatment. If a social infraction is suspected on the part of the afflicted, then a confession may be required and regret communicated in some way. Purification may be required in the form of ritual washing with magically infused water or the blood of a sacrificial animal. Stop Buruli Consortium researchers from all three index countries found that when herbal medicines are employed, medicines are commonly applied to dry a wound. Drying is seen as necessary for the healing process [34]. In some cases, burning or cutting a patient to remove bad blood may be undertaken. Interdictions may also be required in the form of prohibitions, which may involve various kinds of food, contact with others during treatment, and/or suspension of sexual relations on the part of the patient. When witchcraft or a spirit's presence is suspected, herbs and mystical protection offered by a traditional healer are commonly thought necessary even if biomedical treatment is eventually sought.

There has been heated discussion within the international Buruli research community about whether traditional healers should play a role in BU outreach and whether collaboration with health staff is feasible. Two factors that emerge from the literature as key to collaboration are an appreciation for dual illness causality, and mutual respect. Stated more succinctly, collaboration depends on whether the expertise of healers is acknowledged when it comes to dealing with psychosocial and mystical aspects of patients' BU experience as the "work of culture" [35]. The "work of culture" refers to the process whereby distressful states, perceived risk and motives, negative affects, and sensations are transformed into publicly accepted sets of meanings and symbols that can be manipulated or dealt with in some culturally salient manner. On the part of traditional healers, there has to be recognition of the expertise of clinical staff in treating BU wounds as a systemic health problem

\footnotetext{
${ }^{3}$ Also see Pearson for a detailed study of why herbalists are preferred for treatment of ulcers, boils, and BU in Uganda.
} 
requiring timely referral and treatment adherence. In short, collaboration requires task sharing.

Few rigorous studies have been carried out to date to test the conditions under which collaborative relations between hospital staff and healers might be established toward the end of managing BU. One exception is a pilot project in Bankim, Cameroon [16]. The project is briefly summarized below in a section on social science inspired interventions. The project was successful in establishing long-term collaborative relations between traditional healers, health staff, and community volunteers. Findings of this study as well as observations made in Obom, Ghana suggest that in regions where healer groups are supported by chiefs and well functioning, it is far easier to establish collaborative agreements and lines of referral than where such groups do not exist. In the case of Bankim, healer groups signed a contract specifying that they would treat suspected cases of BU for 10 days or less, and not treat a patient's skin. Health staff in return granted traditional healers privileges to visit patients in health posts and offer spiritual protection and psychosocial support.

Three lessons learned in the Bankim case study may be highlighted. First, before introducing training courses for healers in general, it was found important to work with a select group of healers to establish best practices. These healers then served as role models for other healers. Second, it was necessary to insure that collaboration was a win-win proposition. Credit for healing a patient was shared between traditional healers and health staff, so that the reputation of both increased. Third, offering incentives to traditional healers to refer BU cases to hospital was found to be a culturally sensitive issue that needed to be handled carefully. In Bankim, traditional healer collaboration was not established by offering cash payments to healers for patient referrals. While an honorarium enabling a healer to bring a patient to a clinic was greatly appreciated, this had to be done in such a way that there was not a perception that healers gained from the sale of sick bodies to the hospital. This would render them morally suspect. One reason for this is that traditional healers are thought capable of engaging in witchcraft to generate more cases. Healers valued the symbolic capital they gained from collaborating with health staff more than the honorarium they received. This was documented in an impact evaluation conducted after funds for honorariums were no longer available. What traditional healers lost in terms of direct and indirect payments for treating BU cases was eclipsed by a rise in their status. The respect they received from health staff at outreach functions and in the hospital increased their status and was highly valued.

In Benin, Johnson et al. [33] supported collaboration with traditional healers in principle, but latter, some of the same authors urged caution when considering healer participation in BU programs based on their experience offering ad hoc training to a few independent healers. Following the training, a few of these healers represented themselves as BU treatment experts and kept instead of referring cases [36]. A more recent study in Benin, however, identified conditions under which healers were willing to refer cases and collaborate with health staff and community volunteers. In a region of the country where decentralized care was recently 
introduced for BU and other chronic ulcers, the popularity of clinic-based treatment soared due to the demonstration effect of good wound management and culturally sensitive outreach education [30]. Traditional healers responded by wanting to be associated with the community based BU outreach efforts being promoted. As in the case of Bankim, traditional healers did not see collaboration as a loss of status when invited to be part of outreach activities and offered respect.

Concern about cost and labor loss have been identified as major factors leading to the consultation of traditional healers who live near the afflicted, and are often relatives [37]. It is important to recognize the accessibility of healers as an important factor influencing health seeking behavior, but it would be simplistic to conclude that accessibility is the only reason traditional healers are consulted at different stages of health problems. As noted by many medical anthropologists (cf. $[38,39])$, traditional healers are consulted before or in conjunction with biomedical care for myriad reasons having social and cultural salience. Some social scientists have argued that patient delay as a result of visiting traditional healers will cease to be a "problem" once adequate BU care is provided by the government [40] or educating the population [41] will lead them to give up superstitions. Based on a review of the BU literature to date, it would be premature if not erroneous to conclude that traditional healing remains popular only because of a lack of affordable biomedical care.

At the same time, it is important to recognize that healers are often chosen over poorly staffed and resourced health facilities. Hausermann [42] presents a compelling case study of health care seeking for BU in a border region of Ghana-Cote d'Ivoire to make this case as well as to call attention to the impact of poorly implemented BU health policy. Hausermann documents the disjunction between official policy narratives about BU and the lived experiences of people in endemic regions. Following the work of medical anthropologist Stacey Langwick [43] in Tanzania, her analysis shows that nurses refer patients to healers in part due to the inadequacies of health posts under their charge. She raises an issue long debated in international/global health. Is government support for the involvement of traditional healers (and community health volunteers) really about providing more holistic patientcentered care or deflecting attention from the shortcomings of the health system and those responsible for developing and implementing policy?

\section{Enabling Factors}

Studies of health care seeking in all three index countries have reported that enabling factors are a major reason for delays in seeking treatment at hospitals and health posts $[9,10,16,20,24,41,44,45]$. Enabling factors include the seasonal availability and cost of transportation, direct and indirect treatment costs, and opportunity costs in the form of labor loss, especially during peak agricultural seasons. Despite free antibiotic treatment for BU, these costs can be catastrophic [44-46]. ${ }^{4}$ Another enabling factor is the identification of appropriate substitute caretakers for children

${ }^{4}$ Chukwuet al. [38] points out that the high costs of pre-diagnosis treatment for BU in Ghana can also put households in a precarious situation. 
left at home when a mother needs to travel to receive treatment for herself or a child [28]. For this reason it is important to look at the household as a unit of analysis [45, $48]$ and to employ a household production of health $[49,50]$ lens when examining BU health care decisions and patient abandonment. ${ }^{5}$ Another useful lens employed by researcher Ines Agbo [28] is that of gender. A consideration of gender relations leads us to an appreciation of the impact BU treatment has on social networks beyond the immediate household of the afflicted given that assistance is commonly requested from extended kin during times of need. Agbo et al. draw attention to the ripple effect of BU beyond households as well as the impact that requests for assistance on social relations over time [29].

Interventions offering patient support have been piloted in each of the three index countries (Benin: Ouinhi, Cameroon: Bankim, Ghana: Obom and Agogo). In each case, when free transportation to health posts and/or free food is offered to patients, clinic popularity increased and treatment delay and treatment drop-out decreased $[16,31,40,51]$.

\subsection{Service Level Factors Affecting Health Care Seeking and Treatment Adherence}

Several service related factors have been identified as leading to treatment delay, drop out, and perceptions of quality of care. Factors identified by social scientists beyond cost, waiting time, and lack of resources at health posts include poor staffpatient communication about the wound healing process, patient concern about prolonged hospital visits with little feedback on likely duration, and fear of amputation and skin grafts [52]. Other concerns reported related to bandaging and pain management. In the case of bandaging, concerns were raised not only about the procedure itself, but the person doing the bandaging. If the intention of the person bandaging toward the patient was not positive, there was concern the healing process would be delayed. And in Ghana concern was raised if a pregnant nurse did a patient's bandaging as her condition was thought to impede healing [34]. In the case of pain, a common perception was that pain was not appreciated or responded to by clinic staff, leading patients to often seek medicines for pain from the market or traditional healers. The most serious concern reported to researchers was lack of trust in clinic staff by patients in some clinical settings [19]. The positive impact of establishing trust through culturally sensitive education outreach, proactive CHWs, and psychosocial as well as material support for patients has been demonstrated at NGO and mission-supported hospitals treating BU cases such as the Agogo Presbyterian Hospital and the Global Evangelical Mission Hospital serving the Ashanti region of

\footnotetext{
${ }^{5}$ The household production of health conceptual framework analyzes practices in which household members engage to maintain, protect, and promote health, as well as how household members respond to health related issues. The HHPH model situates health and illness within the larger environment of activities occurring in households and thus provides a valuable complementary component to the study of health care seeking.
} 
Ghana [51, 53], and the clinic and community-based interventions described below. An issue not adequately investigated is what kind of incentives might keep community stakeholders and clinic staff in different settings motivated [30, 36], and what factors might strengthen as well as weaken collaborative relationships. Social scientists tend to think of incentives in terms of different types of convertible capital (economic, cultural, social, symbolic; $[54,55]$ ). In need of consideration are the ramifications of offering different types of capital as incentives in various ways in different cultural settings, and the impact of these incentives on both the identity of stake holders and teamwork.

\section{Part Two: Social Science Inspired Interventions}

Social scientists have worked closely with their public health/medical colleagues in developing, testing, and implementing health service interventions to raise the consciousness of community members about BU in an effort to detect and treat cases earlier, reduce treatment no-show and drop-out, and increase treatment adherence. Interventions have been mounted in the areas of outreach education, patient support, community stakeholder collaboration, the formation of BU communities of practice, and the transforming of hospitals for long-term patients into therapeutic communities. In this review I briefly highlight seven interventions that have gone beyond offering food and transport to outpatients as forms of support. All seven interventions were sponsored by the Stop Buruli Consortium. For more information on the Stop Buruli Initiative the reader is referred to chapter "Transdisciplinary Research and Action to Stop Buruli Ulcer: A case Study from Philanthropy" of this book.

\subsection{Outreach Education}

An innovative form of outreach education was introduced in Benin, Cameroon, and Ghana based on a review of research documenting what community members did and did not know about BU, misconceptions about BU and its treatment, awareness of the availability of free treatment, and concerns about treatment. This intervention served as a foundation for building a new generation of community-based BU interventions, and the cornerstone for building BU communities of practice (described below).

The outreach program adopted a question-answer format and iterative process. In brief, the program employed an image-rich PowerPoint presentation on BU delivered by local teams equipped with portable generators and sound systems, laptop computers, and LCD projectors. Outreach meetings were interactive, not passive, and questions were invited from community members. Social scientists recorded and investigated how best to respond to questions posed in a way that was at the same time scientific and understandable to local audiences. Messages and visuals were tested and changed as needed. The following table summarizes the ten major sections of the outreach program (Table 1). Notably, specific sets of messages were designed to inform and educate the community about BU, reassure community members about the quality of care available at hospitals and health posts, offer hope 
Table 1 Format of Stop Buruli Consortium outreach education

\begin{tabular}{|c|c|c|}
\hline $\begin{array}{l}\text { Ten sections of outreach } \\
\text { education program }\end{array}$ & Key messages conveyed & Issues downplayed or emphasized \\
\hline $\begin{array}{l}\text { Signs and symptoms of } \\
\text { BU, how to recognize } \\
\text { the disease, and the } \\
\text { need to treat it early }\end{array}$ & $\begin{array}{l}\text { Visuals of physical signs of } \\
\text { BU in different stages } \\
\text { Visual and tactile cues } \\
\text { suggesting that a lesion, } \\
\text { abscess ulcer, or edema } \\
\text { may be BU } \\
\text { - Progression of disease if } \\
\text { not treated }\end{array}$ & $\begin{array}{l}\text { Category I and II BU depicted, but } \\
\text { not category III as this evoked } \\
\text { great fear }\end{array}$ \\
\hline $\begin{array}{l}\text { High risk environments } \\
\text { and modes of } \\
\text { transmission }\end{array}$ & $\begin{array}{l}\text { High risk environments } \\
\text { where one is more likely to } \\
\text { be exposed to } \\
\text { Mycobacterium ulcerans } \\
\text { - Focus was on addressing } \\
\text { incorrect ideas about BU } \\
\text { transmission and contagion }\end{array}$ & $\begin{array}{l}\text { Less time and attention allotted to } \\
\text { risk environments and possible } \\
\text { modes of transmission as the } \\
\text { science is inconclusive and } \\
\text { behavior change related to } \\
\text { exposure to water sources difficult } \\
\text { given the local reality }\end{array}$ \\
\hline $\begin{array}{l}\text { What clinic staff do to } \\
\text { determine if the } \\
\text { affliction is BU or } \\
\text { some other disease }\end{array}$ & $\begin{array}{l}\text { Why health staff take swabs, } \\
\text { what they look for under the } \\
\text { microscope, why medicine for } \\
\text { BU is specific and not the } \\
\text { same as medications used for } \\
\text { other ulcers }\end{array}$ & $\begin{array}{l}\text { Step-by-step explanation of what } \\
\text { staff is actually doing along with } \\
\text { pictures to offset fears and rumors } \\
\text { about what they are doing as a } \\
\text { means to increase trust }\end{array}$ \\
\hline $\begin{array}{l}\text { Effective and } \\
\text { ineffective treatments } \\
\text { for BU }\end{array}$ & $\begin{array}{l}\text { Why } 56 \text { days of pills and } \\
\text { injections (or more) are } \\
\text { needed } \\
\text { Why herbal medicine for } \\
\text { this disease does not lead to } \\
\text { a cure even if a wound is } \\
\text { dried }\end{array}$ & $\begin{array}{l}\text { Agricultural analogies used to } \\
\text { convey the idea that medication } \\
\text { is taken beyond treatment for the } \\
\text { visible wound, as a means to get } \\
\text { at the roots and seeds of BU as a } \\
\text { systemic infection in the body } \\
\text { Pictures used to show } \\
\text { inappropriate treatment, how } \\
\text { drying wound is not curing, and } \\
\text { effectiveness of medication } \\
\text { after herbal medicine has failed } \\
\text { to treat the wound }\end{array}$ \\
\hline $\begin{array}{l}\text { Traditional healers } \\
\text { and rapid referral } \\
\text { to hospitals and } \\
\text { health posts } \\
\text { Emphasis on rapid } \\
\text { referral }\end{array}$ & $\begin{array}{l}\text { Positive messages about } \\
\text { exemplar healers who } \\
\text { recognize signs of BU and } \\
\text { rapidly refer patients to clinic } \\
\text { after spiritual protection is } \\
\text { offered }\end{array}$ & $\begin{array}{l}\text { - No message disrespecting local } \\
\text { practices as superstitious } \\
\text { - Respect for traditional healers' } \\
\text { role in offering spiritual protection } \\
\text { for those for whom this is a } \\
\text { concern }\end{array}$ \\
\hline $\begin{array}{l}\text { Quality of care at the } \\
\text { clinic }\end{array}$ & $\begin{array}{l}\text { Quality of care offered by } \\
\text { staff: pictures of what care in } \\
\text { the clinic looks like, } \\
\text { approachable staff, hygienic } \\
\text { conditions, empathetic } \\
\text { caretakers, etc. }\end{array}$ & To offset fear and evoke confidence \\
\hline $\begin{array}{l}\text { Care available free of } \\
\text { charge or subsidized } \\
\text { for BU patients } \\
\text { at clinics }\end{array}$ & $\begin{array}{l}\text { Types of support available } \\
\text { ranging from free medications, } \\
\text { to food, transport, and housing }\end{array}$ & \\
\hline
\end{tabular}


Table 1 (continued)

\begin{tabular}{|c|c|c|}
\hline $\begin{array}{l}\text { Ten sections of outreach } \\
\text { education program }\end{array}$ & Key messages conveyed & Issues downplayed or emphasized \\
\hline $\begin{array}{l}\text { Before and after } \\
\text { pictures of BU related } \\
\text { wounds successfully } \\
\text { treated }\end{array}$ & $\begin{array}{l}\text { Pictures of BU treatment, } \\
\text { and the healing process at } \\
\text { different stages } \\
\text { - Depict the healing of ulcers } \\
\text { on different parts of the } \\
\text { body }\end{array}$ & $\begin{array}{l}\text { Pictures depict children and male } \\
\text { and female patients of different } \\
\text { ages so members of the audience } \\
\text { can personally relate }\end{array}$ \\
\hline $\begin{array}{l}\text { The presentation ends } \\
\text { on a note of hope }\end{array}$ & $\begin{array}{l}\text { Testimonials of patients who } \\
\text { have been cured speak of their } \\
\text { experiences and to the quality } \\
\text { of care they have received at } \\
\text { the clinic }\end{array}$ & $\begin{array}{l}\text { Open microphone: some } \\
\text { testimonials are planned and others } \\
\text { are spontaneous }\end{array}$ \\
\hline $\begin{array}{l}\text { Questions from the } \\
\text { audience }\end{array}$ & $\begin{array}{l}\text { On any topic related to } \\
\text { information presented or any } \\
\text { other issue related to BU }\end{array}$ & $\begin{array}{l}\text { Open microphone empowers } \\
\text { people to speak } \\
\text { Questions are recorded and } \\
\text { responses to questions assessed } \\
\text { as part of iterative process of } \\
\text { ongoing research }\end{array}$ \\
\hline
\end{tabular}

of a cure, display stakeholder collaboration, and inform community members about the kind of support available during treatment.

In each of the three countries, large-scale community outreach education meetings were held in the evenings. Community health workers were responsible for organizing meetings and inviting chiefs, local healers, and former patients to attend. This increased their status in the community, enhanced lines of communication with health staff, and motivated them to become more actively involved in BU outreach. In contexts where multiple languages were spoken, CHWs were trained to act as translators from French or English into local dialects. Following community programs, BU screening took place, CHWs accompanied suspected cases to hospital and health posts, and followed up on confirmed cases. The outreach program was piloted in over 200 communities in the three countries and reached an estimated 75,000 people [56]. Evaluations carried out in each country confirmed that the program was effective in identifying significant numbers of BU cases and raising community confidence in clinic based care $[16,30]$.

\subsection{Introducing Decentralized BU Care in Ouinhi, Benin}

Although decentralized treatment of category I and II BU cases has been well established in several regions of Benin, it has not been introduced into the Ouinhi region. In this endemic region, centralized hospital care and surgery was the norm. Despite outreach efforts by a very proactive Catholic mission hospital, few early category I BU cases were brought to the hospital due in large part to fear of surgery. In the intervention, two local nurses were trained in the decentralized treatment of BU along with other types of chronic wounds. Outreach education programs were conducted 
and a message delivered that outpatient care was now available at local health posts for BU, and that staff had been trained to treat chronic wounds and early stages of BU without surgery. The community responded well to the intervention [30]. Self-referral following outreach programs increased significantly and many category I cases were treated at the clinic. Notably, over $70 \%$ of all BU cases brought to the clinic and confirmed as BU could be treated by decentralized care with over a $90 \%$ success rate. Community volunteer groups were established by social scientists to ensure that patients finished a complete course of medications and followed wound care advice. A lesson learned was the importance of treating all chronic wounds in the community as a means of establishing broad based clinic credibility. This project inspired research currently underway to develop a pragmatic approach to clinic and community based wound care management in Benin and Cote d'Ivoire.

\subsection{Establishing a BU Community of Practice: Cameroon}

In Cameroon, previous efforts to identify BU through the mobilization of CHWs yielded poor results. A majority of BU cases were first treated by traditional practitioners and few cases of category I BU were seen at hospital or health stations. Social scientists established a successful BU community of practice (BUCOP). A community of practice (COP) is an assemblage of stakeholders committed to a common objective, a common basic understanding of a focal problem, and mutual respect for what each stakeholder contributes to a process of problem-solving. In the case of BU, this entails health staff, $\mathrm{CHWs}$, and traditional healers sharing a common understanding of the signs of BU, collaboration in encouraging the afflicted to seek and continue BU treatment, open lines of communication between stakeholders, and mutual respect for what each contributes to the process of healing that includes, but extends beyond the management of $\mathrm{BU}$ as a disease.

The success of the BUCOP has been measured in terms of numbers of suspected BU cases referred and confirmed, decline in patient treatment drop-out, and sustained collaboration among stakeholders both during and following the 3-year pilot project. The pilot project implemented the aforementioned BU outreach education program, increased levels of patient assistance beyond food and transport to include setting up halfway houses where patients could reside during treatment if they came from distant places, and established close working relations with traditional practitioners groups. Traditional healers not only referred cases of suspected BU to health posts; they also participated in outreach programs, and at the invitation of health staff provided psychosocial support for hospital patients. Nearly all of the 50 traditional healers participating in the BUCOP adhered to a collaboration contract, and after 2 years were presented with identification badges by district health authorities based upon their performance.

The success of the pilot project is far beyond what researchers had thought possible to achieve [16]. During the project over $90 \%$ of suspected and confirmed cases of BU seen at the Bankim hospital were referred by community stakeholders. Many category I BU cases were identified and treated successfully, and ethnic groups like 
the Fulani that previously had not sought treatment at the hospital began doing so. Notably, following 3 years of mass outreach education programs, the large majority of BU cases seen in Bankim Hospital were self-referred. Community members commonly checked with CHWs and healers if they suspected a case of BU before bringing the afflicted to a clinic. The status of healers, CHWs and the hospital all improved.

\subsection{Yaws Cases Identified as a Result of BU Outreach in Cameroon: A Case for Integrated Skin Neglected Tropical Disease (NTD) Programs}

One unanticipated outcome of BU outreach in Bankim, Cameroon was the identification of cases of yaws. Up until a household survey identified 29 cases of yaws, a year before the intervention [57], yaws was thought to be rare, if not eliminated. It had not been seen at hospital or health posts in Bankim district for years. Mass BU outreach programs attracted community members with other chronic skin diseases. When yaws cases were recognized by health staff during wound screening, schools in the community were also screened. Over 850 cases of yaws were identified and treated [58]. This illustrates the effectiveness of mass outreach programs as well as the potential of integrated NTD programs. Notably, the demonstration effect of yaws treatment requiring only a single dose of azithromycin or penicillin, increased community confidence in clinic treatment for BU.

\subsection{BU Children's Support Group Ghana}

In Ghana a children's program was developed to accompany the community-based outreach program. The necessity for this intervention became clear when it was discovered that children having BU were stigmatized by classmates and often dropped out of school. Teachers did not intervene nor follow up on such children. Stop Buruli researcher Eric Koka realized that in addition to providing education about BU to students and teachers, the negative perception of BU needed to be transformed. An intervention was introduced that had three parts. First, students with category I-II BU were offered free transportation by motorcycle to a clinic, where they were treated and then returned to school. Motor cycle taxi rides are seen by children as an exciting adventure. Once at the clinic children were also given a nutritious snack, which they relished. A second component was establishing a peer mentorship program. Children who had been successfully treated mentored new patients and helped them deal with the fear of daily injections and informed them about the healing process, as well. Children found having a peer mentor reassuring. Third, an BU patients club was formed. T-shirts identifying patients and ex-patients were proudly worn and members were asked to be on the lookout for new cases as well as to give testimonials on the healing process at school. 
Eleven former patients' clubs were formed between 2011 and 2014 involving 132 school children. Most of the club members were between the ages of 6 and 18 years with a median age of 12 years. A more positive and less stigmatized identity created by club activities contributed to more children willing to come for treatment, and more parents willing to have their children screened and treated. In the 3 years prior to the intervention (2007-2010) 18 of the $32 \mathrm{BU}$ patients attending Obom health centre were school children. During the 3 years of the intervention (2011-2014) the number of BU cases increased to 273 of which 145 were children. Notably, out of the 145 school children receiving treatment, 138 were category one cases, and $42(30 \%)$ were referred by members of the children's BU club [59].

\subsection{Mhealth as a Tool in Monitoring BU Healing in Ghana}

Social scientist Mercy Ackumey teamed up with physician Nana Kotey to experiment with using mobile phones to monitor wound and scar care in Ghana. Oral therapy has been on the horizon of BU care for some time and in 2017 the WHO Technical Advisory Group on BU provisionally recommended treatment with oral clarithromycin and rifampicin pending the full results of a clinical trial. Anticipating this therapeutic option, the researchers deemed it imperative to test how wound care might be monitored by mobile phone if patients were not visiting health posts daily for BU treatment. Mobile phones are widely available in the region of Ghana where the project took place. The team created a check list of possible signs of a wound that was not healing well. Using the check list, short, semi-structured phone calls were made to patients and questions asked about the status of their wound. If danger signs were indicated, the patient was asked to visit the clinic. Patients found the calls reassuring and the intervention enhanced the reputation of the clinic. The pilot project identified several issues that will need to be addressed in the future should the approach go to scale [60].

\subsection{Transforming a BU Hospital into a Therapeutic Community for Inpatients}

Reducing social distance between hospital staff and patients and establishing clear lines of communication is a major challenge when providing in-patient care for people afflicted by BU and other chronic ulcers. Research on hospitals as therapeutic communities is virtually non-existent in Africa. An ethnography of Allada reference hospital in Benin responsible for treating $\mathrm{BU}$ and other chronic ulcers identified several sources of psychosocial distress and communication patterns compromising quality of care. Based on this research, an intervention was mounted to transform the hospital into a higher functioning therapeutic community. Question-answer education sessions were introduced to provide patients the opportunity to inquire about their illness and its treatment and trajectory, weekly open-forums were established 
to give patients and hospital staff a chance to air grievances, patient representatives met with hospital staff to resolve problems related to daily living in a non-confrontational manner, and psychosocial support for individual patients was provided through drop-in counseling sessions with social scientists in residence.

Patients reported positive changes in the quality of their care and interactions with care providers, care providers reported that the problem-solving process instituted was productive, and hospital administrators actively supported efforts to improve social relations and lines of communication [52]. Former patients were seen as a community outreach resource as both expert patients and ambassadors of the National BU control program were able to speak firsthand about the disease and the quality of care being offered. One systemic problem identified in both this and the Bankim project was community response to linear disease focused programs. Preferential treatment for BU patients in the form of subsidized treatment supported by the government and international funding agencies was deeply resented by patients being treated for other chronic wounds and who had to pay for their treatment out of their pocket. As far as patients and community members could see, all chronic wounds appear to warrant the same level of clinical attention, and special care for BU could not be defended on the basis of being contagious and therefore a community wide risk like TB.

\section{Conclusion}

Social science has contributed in important ways to health service research related to BU and to the development and testing of innovative community and clinic based interventions. This brief overview of research illustrates the importance of using mixed methods to investigate predisposing, enabling, and service related factors influencing health care seeking, treatment adherence, and subjective perceptions of quality of care. It also draws attention to the importance of community outreach and the active participation of community stakeholders in BU programs. This entails giving community health volunteers, former patients, and traditional healers a proactive and not just a passive role in outreach and patient support, learning how to establish respectful partnerships and effective lines of communication, and assessing how to keep all stakeholders motivated. Lessons learned from the BU interventions highlighted in this chapter have broad relevance to other NTD and (re)emerging disease preparedness programs. They also illustrate why integrated skin NTD and wound care programs are needed and ways in which linear programs, privileging the care of one kind of chronic wound over another, undermine community trust.

\section{References}

1. Kroeger A (1983) Anthropological and socio-medical health care research in developing countries. Soc Sci Med 17(3):147-161

2. Konan DO, Mosi L, Fokou G, Dassi C, Narh CA, Quaye C, Saric J, Abe NN, Bonfoh B (2018) Buruli ulcer in southern Côte D'ivoire: dynamic schemes of perception and interpretation of modes of transmission. J Biosoc Sci:1-14 
3. Pearson G (2018) Understanding perceptions on 'Buruli' in northwestern Uganda: a biosocial investigation. PLoS Negl Trop Dis 12(7):e0006689

4. Grietens KP, Toomer E, Boock AU, Hausmann-Muela S, Peeters H, Kanobana K, Gryseels C, Ribera JM (2012) What role do traditional beliefs play in treatment seeking and delay for Buruli ulcer disease?-insights from a mixed methods study in Cameroon. PLoS One 7(5):e36954

5. Glick LB (1967) Medicine as an ethnographic category: the gimi of the New Guinea highlands. Ethnology 6(1):31-56

6. Nichter M (1987) Kyasanur forest disease: an ethnography of a disease of development. Med Anthropol Q 1(4):406-423

7. Good BJ, Good MJ, Togan I, Ilbars Z, Güvener A, Gelişen I (1994) In the subjenctive mode: epilepsy narratives in Turkey. Soc Sci Med 38(6):835-842

8. Whyte SR (2005) Uncertain undertakings: practicing health care in the subjunctive mood. In: Managing uncertainty. Museum Tusculanum, Copenhagen, pp 245-264

9. Mulder AA, Boerma RP, Barogui Y, Zinsou C, Johnson RC, Gbovi J, van der Werf TS, Stienstra Y (2008) Healthcare seeking behaviour for Buruli ulcer in Benin: a model to capture therapy choice of patients and healthy community members. Trans R Soc Trop Med Hyg 102(9):912-920

10. Aujoulat I, Johnson C, Zinsou C, Guédénon A, Portaels F (2003) Psychosocial aspects of health seeking behaviours of patients with Buruli ulcer in southern Benin. Trop Med Int Health 8(8):750-759

11. Kpadonou TG, Alagnidé E, Azanmasso H, Fiossi-Kpadonou E, Moevi AH, Niama D, Houngbédji G (2013) Psychosocioprofessional and familial becoming of formers Buruli ulcer patients in Benin. Ann Phys Rehabil Med 56(7-8):515-526

12. Boyer MN (2017) Questioning assumptions about decision-making in West African households: examples from longitudinal studies in Benin and Mali. PhD Dissertation, University of Arizona

13. Good BJ (1977) The heart of what's the matter the semantics of illness in Iran. Cult Med Psychiatry 1(1):25-58

14. Kennell J (2011) The senses and suffering: medical knowledge, spirit possession, and vaccination programs in Aja. $\mathrm{PhD}$ dissertation, Southern Methodist University

15. Sargent C, Kennell JL (2017) Elusive paths, fluid care. In: Olsen WC, Sargent C (eds) African medical pluralism. Indiana University Press, Indianapolis, p 227

16. Awah PK, Boock AU, Mou F, Koin JT, Anye EM, Noumen D, Nichter M, Stop Buruli Consortium (2018) Developing a Buruli ulcer community of practice in Bankim, Cameroon: a model for Buruli ulcer outreach in Africa. PLoS Negl Trop Dis. 12(3):e0006238

17. Giles-Vernick T, Owona-Ntsama J, Landier J, Eyangoh S (2015) The puzzle of Buruli ulcer transmission, ethno-ecological history and the end of "love" in the Akonolinga district, Cameroon. Soc Sci Med 129:20-27

18. Leach M, Scoones I (2013) The social and political lives of zoonotic disease models: narratives, science and policy. Soc Sci Med 88:10-17

19. Renzaho A, Woods PV, Ackumey MM, Harvey SK, Kotin J (2007) Community-based study on knowledge, attitude and practice on the mode of transmission, prevention and treatment of the Buruli ulcer in Ga West District, Ghana. Tropical Med Int Health 12(3):445-458

20. Ackumey MM, Gyapong M, Pappoe M, Maclean CK, Weiss MG (2012) Illness meanings and experiences for pre-ulcer and ulcer conditions of Buruli ulcer in the Ga-West and Ga-South Municipalities of Ghana. BMC Public Health 12(1):264

21. Ackumey MM, Gyapong M, Pappoe M, Weiss MG (2011) Help-seeking for pre-ulcer and ulcer conditions of Mycobacterium ulcerans disease (Buruli ulcer) in Ghana. Am J Trop Med Hyg 85(6):1106-1113

22. Owusu AY, Adamba C (2012) Household perceptions, treatment-seeking behaviour and health outcomes for Buruli ulcer disease in a peri-urban district in Ghana. Adv Appl Sociol 2(3):179_ 186. https://doi.org/10.4236/aasoci.2012.23024 
23. Koka E (2018) Community knowledge and perceptions about Buruli ulcers in Obom SubDistrict of the Ga south municipality in the Greater Accra region of Ghana. Adv Appl Sociol 8(09):621

24. Stienstra Y, van der Graaf WT, Asamoa K, van der Werf TS (2002) Beliefs and attitudes toward Buruli ulcer in Ghana. Am J Trop Med Hyg 67(2):207-213

25. Tschakert P, Ricciardi V, Smithwick E, Machado M, Ferring D, Hausermann H, Bug L (2016) Situated knowledge of pathogenic landscapes in Ghana: understanding the emergence of Buruli ulcer through qualitative analysis. Soc Sci Med 150:160-171

26. de Zeeuw J, Omansen TF, Douwstra M, Barogui YT, Agossadou C, Sopoh GE, Phillips RO, Johnson C, Abass KM, Saunderson P, Dijkstra PU (2014) Persisting social participation restrictions among former Buruli ulcer patients in Ghana and Benin. PLoS Negl Trop Dis 8(11):e3303

27. Ribera JM, Grietens KP, Toomer E, Hausmann-Muela S (2009) A word of caution against the stigma trend in neglected tropical disease research and control. PLoS Negl Trop Dis 3(10):e445

28. Agbo I (2015) The gendered impact of Buruli ulcer on the household production of health: why decentralization favors women. Tropical Med Int Health 20:298

29. Agbo I, Johnson C, Sopoh G, Nichter M (2019) The gendered impact of Buruli ulcer on the household production of health and social beyond: why decentralization favors women. Plos (forthcoming)

30. Amoussouhoui AS, Sopoh GE, Wadagni AC, Johnson RC, Aoulou P, Agbo IE, Houezo JG, Boyer M, Nichter M (2018) Implementation of a decentralized community-based treatment program to improve the management of Buruli ulcer in the Ouinhi district of Benin, West Africa. PLoS Negl Trop Dis 12(3):e0006291

31. Ackumey MM, Kwakye-Maclean C, Ampadu EO, de Savigny D, Weiss MG (2011) Health services for Buruli ulcer control: lessons from a field study in Ghana. PLoS Negl Trop Dis $5(6): \mathrm{e} 1187$

32. Webb BJ, Hauck FR, Houp E, Portaels F (2009) Buruli ulcer in West Africa: strategies for early detection and treatment in the antibiotic era. East Afr J Public Health 6:144-147

33. Johnson RC, Makoutode M, Hougnihin R, Guédénon A, Ifebe D, Boko M, Portaels F (2004) Le traitement traditionnel de l'ulcere de Buruli au Benin. Med Trop 64(2):145-150

34. Koka E, Yeboah-Manu D, Okyere D, Adongo PB, Ahorlu CK (2016) Cultural understanding of wounds, Buruli ulcers and their management at the Obom sub-district of the Ga south municipality of the Greater Accra region of Ghana. PLoS Negl Trop Dis 10(7):e0004825

35. Nichter M (2008) Coming to our senses: appreciating the sensorial in medical anthropology. Transcult Psychiatry 45(2):163-197

36. Barogui YT, Sopoh GE, Johnson RC, de Zeeuw J, Dossou AD, Houezo JG, Chauty A, Aguiar J, Agossadou D, Edorh PA, Asiedu K (2014) Contribution of the community health volunteers in the control of Buruli ulcer in Benin. PLoS Negl Trop Dis 8(10):e3200

37. Ackumey MM, Gyapong M, Pappoe M, Maclean CK, Weiss MG (2012) Socio-cultural determinants of timely and delayed treatment of Buruli ulcer: implications for disease control. Infect Dis Poverty 1(1):6

38. Labhardt ND, Aboa SM, Manga E, Bensing JM, Langewitz W (2010) Bridging the gap: how traditional healers interact with their patients. A comparative study in Cameroon. Trop Med Int Health 15(9):1099-1108

39. Nichter M, Quintero G (1996) Pluralistic therapy systems: why do they co-exist and how are they used. In: Levinson D, Ember M (eds) Encyclopedia of cultural anthropology. Henry Holt, New York, pp 1-17

40. Ahorlu CK, Koka E, Yeboah-Manu D, Lamptey I, Ampadu E (2013) Enhancing Buruli ulcer control in Ghana through social interventions: a case study from the Obom sub-district. BMC Public Health 13(1):59

41. Owusu-Sekyere E (2013) The buruli ulcer morbidity in the amansie West District of Ghana: a myth or a reality? J Pub Health Epidemiol 5(10):402-409

42. Hausermann HE (2015) 'I could not be idle any longer': buruli ulcer treatment assemblages in rural Ghana. Environ Plan A 47(10):2204-2220 
43. Langwick SA (2008) Articulate (d) bodies: traditional medicine in a Tanzanian hospital. Am Ethnol 35(3):428-439

44. Asiedu K, Etuaful S (1998) Socioeconomic implications of Buruli ulcer in Ghana: a three-year review. Am J Trop Med Hyg 59(6):1015-1022

45. Grietens KP, Boock AU, Peeters H, Hausmann-Muela S, Toomer E, Ribera JM (2008) "It is me who endures but my family that suffers": social isolation as a consequence of the household cost burden of Buruli ulcer free of charge hospital treatment. PLoS Negl Trop Dis 2(10):e321

46. Amoakoh HB, Aikins M (2013) Household cost of out-patient treatment of Buruli ulcer in Ghana: a case study of Obom in Ga south municipality. BMC Health Serv Res 13(1):507

47. Chukwu JN, Meka AO, Nwafor CC, Oshi DC, Madichie NO, Ekeke N, Anyim MC, Chukwuka A, Obinna M, Adegbesan J, Njoku M (2017) Financial burden of health care for Buruli ulcer patients in Nigeria: the patients' perspective. Int Health 9(1):36-43

48. Goudge J, Govender V (2000) A review of experience concerning household ability to cope with the resource demands of ill health and health care utilisation. EQUINET

49. Berman P, Kendall C, Bhattacharyya K (1994) The household production of health: integrating social science perspectives on micro-level health determinants. Soc Sci Med 38(2):205-215

50. Nichter M, Kendall C (1991) Beyond child survival: anthropology and international health in the 1990s. Med Anthropol Q 5(3):195-203

51. Agbenorku P, Agbenorku M, Amankwa A, Tuuli L, Saunderson P (2011) Factors enhancing the control of Buruli ulcer in the Bomfa communities, Ghana. Trans R Soc Trop Med Hyg 105(8):459-465

52. Amoussouhoui AS, Johnson RC, Sopoh GE, Agbo IE, Aoulou P, Houezo JG, Tingbe-Azalou A, Boyer M, Nichter M (2016) Steps toward creating a therapeutic community for inpatients suffering from chronic ulcers: lessons from Allada Buruli Ulcer Treatment Hospital in Benin. PLoS Negl Trop Dis 10(7):e0004602

53. Abass KM, Van Der Werf TS, Phillips RO, Sarfo FS, Abotsi J, Mireku SO, Thompson WN, Asiedu K, Stienstra Y, Klis SA (2015) Buruli ulcer control in a highly endemic district in Ghana: role of community-based surveillance volunteers. Am J Trop Med Hyg 92(1):115-117

54. Bourdieu P (1986) The forms of capital. In: Richardson JG (ed) Handbook of theory and research for the sociology of education. Greenwood Press, New York, pp 241-258

55. Magrath P, Nichter M (2012) Paying for performance and the social relations of health care provision: an anthropological perspective. Soc Sci Med 75(10):1778-1785

56. Nichter M, Amoussouhoui A, Ferdinand M, Koka E, Kum AP, Mbah E, Tohnain K, Boyer M (2015) Buruli ulcer outreach education: an exemplar for community based tropical disease interventions. Oral presentation, World Health Organization Biannual Buruli Conference

57. Bratschi MW, Bolz M, Minyem JC, Grize L, Wantong FG, Kerber S, Tabah EN, Ruf MT, Mou F, Noumen D, Boock AU (2013) Geographic distribution, age pattern and sites of lesions in a cohort of Buruli ulcer patients from the Mapé Basin of Cameroon. PLoS Negl Trop Dis 7(6): 2252

58. Boock AU, Awah PK, Mou F, Nichter M (2017) Yaws resurgence in Bankim, Cameroon: the relative effectiveness of different means of detection in rural communities. PLoS Negl Trop Dis 11(5): $\mathrm{e} 0005557$

59. Koka E, Okyere D, Aboagye S, Ahorlu CK, Yeboah-Manu D, Nichter M. Mobilising youth in support of Buruli ulcer outreach in Southern Ghana: lessons learned from former patients groups. Unpublished manuscript

60. Ackumey M, Kotey NK, Nichter M (2015) Using cell phones to improve compliance to treatment and monitor wound care in the Nsawam-Adoagyiri and Akwapem-South Districts of Ghana. Oral presentation at World Health organization Biannual Buruli Conference, March 24,2015 
Open Access This chapter is licensed under the terms of the Creative Commons Attribution 4.0 International License (http://creativecommons.org/licenses/by/4.0/), which permits use, sharing, adaptation, distribution and reproduction in any medium or format, as long as you give appropriate credit to the original author(s) and the source, provide a link to the Creative Commons license and indicate if changes were made.

The images or other third party material in this chapter are included in the chapter's Creative Commons license, unless indicated otherwise in a credit line to the material. If material is not included in the chapter's Creative Commons license and your intended use is not permitted by statutory regulation or exceeds the permitted use, you will need to obtain permission directly from the copyright holder.

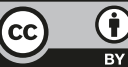

